This is the accepted manuscript, which has been accepted by IEEE for publication.

(C) 2010 IEEE. Personal use of this material is permitted. Permission from IEEE must be obtained for all other uses, in any current or future media, including reprinting/republishing this material for advertising or promotional purposes, creating new collective works, for resale or redistribution to servers or lists, or reuse of any copyrighted component of this work in other works. The full reference is:

'Performance of Silicone Rubber in DC Inclined Plane Tracking Tests'

G. P. Bruce and S. M. Rowland and A. Krivda

IEEE Transactions on Dielectrics and Electrical Insulation, Vol. 17, Issue 2, pp. 521-532, April 2010

DOI: $\underline{\text { 10.1109/TDEI.2010.5448108 }}$ 


\title{
Performance of Silicone Rubber in DC Inclined Plane Tracking Tests
}

\author{
G. P. Bruce and S. M. Rowland \\ School of Electrical and Electronic Engineering \\ University of Manchester, Manchester, M60 1QD, UK \\ and A. Krivda \\ ABB Switzerland Ltd, Corporate Research, Baden-Daettwil, Switzerland
}

\begin{abstract}
The inclined plane tracking and erosion test IEC-60587 is not specified for DC testing. A de test has been developed from the current ac standard and three formulations of silicone rubber tested. These materials were tested under three voltage levels $(2.3,2.7$ and $3.2 \mathrm{kV}$ ) for both polarities. Positive dc tests have the highest average and peak leakage current and exhibit a higher degree of surface damage. The observed surface degradation pattern is heavily dependant on polarity. Consistently higher levels of erosion have been observed in the higher voltage positive cases. Erosion of the surface always starts at the bottom electrode, and spreads toward the top electrode. Puncturing of the $6 \mathrm{~mm}$ thick samples or deep erosion over more than half the distance between electrodes has only been observed under 2.7 and $3.2 \mathrm{kV}$ positive polarity tests. Results have been analysed using a variety of leakage current analysis techniques going beyond the criteria specified in the original ac standard. The low-frequency behaviour of the leakage current was monitored using a 15 sample per second current recorder. The leakage current magnitude is investigated in a case study and is shown to follow a normal distribution. Reversing the polarity of tests shows the leakage current seen in a test is largely independent of the surface degradation pattern present, but the surface degradation pattern over the first three hours may dictate the morphology of ensuing deep erosion
\end{abstract}

Index Terms - Silicone rubber, IEC 60587, dc, electrical discharge, tracking, erosion.

\section{INTRODUCTION}

THE increasing market share of high voltage direct current $(\mathrm{HVdc})$ technology in power transmission and distribution drives the need to understand the reliability of dc outdoor insulation. Such systems have been used in submarine cable links for many years. Above water the technology is often used for long distance transmission where it is more economic and energy efficient than ac. In almost all new-builds, replacements and upgrades, silicone rubber (SIR) composite insulators are an attractive alternative to traditional ceramic insulators. This has been the driving force for much research on SIR including ac tracking and erosion tests. Combining HVdc technology and the SIR composite insulator offers many advantages and forms the rationale for the research in this paper.

Manuscript received on 7 May 2009, in final form 6 July 2009.
Composite insulators typically weigh $10 \%$ of the equivalent ceramic insulator. This can reduce transport and installation costs, but it also means that the supporting structure has a lower total mechanical load. Because the manufacturing processes of ceramics and composite insulators differ, the composite insulator designs look very different: they are generally a lot thinner, have shorter overall length, and as a result transmission lines can be more aesthetically pleasing. SIR insulators also have superior electrically insulating properties mainly attributed to their hydrophobicity.

An insulator may be expected to be in service for 25 years or more. This service life however depends on the rate of insulator degradation, which itself is determined by environmental and electrical stresses. The ac tracking and erosion test IEC-60587 allows the comparison of different materials under a controlled electrical stress, in order to compare the suitability of materials for the dielectric surface of an insulator. It is not an accelerated ageing test as compared to the rotating-wheel-dip test IEC 1302, but is a valuable tool for the evaluation and comparison of different and new materials [1]. 
There are two key processes responsible for decomposition of the SIR by rapid localised heating. Aluminium trihydrate (ATH) filler decomposes in an endothermic reaction at around $200{ }^{\circ} \mathrm{C}$ to form aluminium oxide and water vapour. This process is said to reduce local surface temperature and prevent damage to the base material. At higher temperatures, the thermal decomposition of the base material results in erosion and leaves silica tracks, powder or char on the surface.

Meyer et al. have correlated eroded mass with temperature using a laser ablation technique [2]. This shows, from damage onset at approximately $300{ }^{\circ} \mathrm{C}$, there is an exponential growth in eroded mass with temperature. Furthermore, eroded mass can be correlated directly with the $3^{\text {rd }}$ harmonic of the associated ac leakage current and used to signify dry band arc activity [3].

Previous studies of dc tracking tests on SIR have concluded that tracking is more severe under dc conditions than for ac [4]. Moreno et al. showed, under positive dc this was associated with increases in magnitude and duration of discharges [4]. There is also evidence that tracking time is less under negative dc than positive dc and the magnitude of current flow is higher under negative dc as compared to positive [5]. Investigation of wavelet transforms has shown that the current flow under negative dc voltage is generally less intermittent and with a higher magnitude than under positive dc [6]. The work here has developed a systematic test to explore these issues further.

\section{EXPERIMENTAL}

Figure 1, shows the experimental setup, which conforms to IEC-60587, with the exception that a dc power source is used. The dc is generated using a single phase full bridge rectifier, and smoothing is provided by an $81 \mu \mathrm{F}$ capacitor. To ensure voltage ripple is minimised and remains below the specified tolerance of $5 \%$, one sample is tested at a time. In the above circuit, the measured voltage ripple for a single $60 \mathrm{~mA}$ load through a $31.5 \mathrm{k} \Omega$ resistor is $28 \mathrm{~V}$ or 1.5 $\%$ of the supply voltage.

Each test is performed according to Method 1, at equivalent supply voltages to 2.5 or $3.5 \mathrm{kV}$ rms [7]. The equivalent dc value was calculated such that the area under the voltage waveforms is equal for ac and $\mathrm{dc}$. The $\mathrm{dc}$ voltages are thus 2.25 , and $3.15 \mathrm{kV} \mathrm{dc}$, with the addition of an intermediate voltage of $2.7 \mathrm{kV}$ dc. The corresponding series resistance values for $2.25,2.7$ and $3.15 \mathrm{kV}$ dc are 11 , 17 and $22 \mathrm{k} \Omega$ respectively. These resistors are chosen to limit the current to $205 \mathrm{~mA}$ and $95 \mathrm{~mA}$ for the lower and higher voltage cases as in the ac method. The intermediate resistance gives an intermediate current limit of $123 \mathrm{~mA}$.

In IEC 60587 the LC based failure conditions are when $60 \mathrm{~mA} \pm 6 \mathrm{~mA}$ or more has persisted in the high-voltage circuit for 2 to 3 seconds, and is typically implemented by an over-current delay relay. The cut-off for this rig is software controlled, and operated when the current is greater than $60 \mathrm{~mA} \pm 0.3 \mathrm{~mA}$ continuously for $2 \mathrm{~s}$. In any case a test is terminated after $6 \mathrm{~h}$, in accordance with test method A.

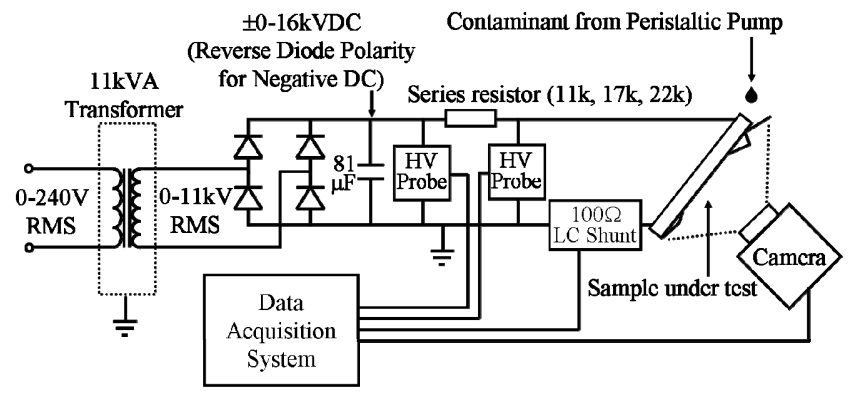

Figure 1. Electrical schematic of experimental setup

The polarity of the supply voltage can be changed by reversing the orientation of the diodes. A positive voltage test is defined as a positive potential on the top electrode and the bottom electrode at ground potential. Similarly, a negative voltage test has a negative potential on the top electrode and the bottom electrode remains grounded.

A detailed description of the monitoring and control system used in this work is given in a previous publication [8]. As illustrated in Figure 1, the data acquisition system captures and displays the following in real-time: supply voltage, sample voltage, leakage current and a colour video of the test sample. A data logger, a 15 sample per second leakage current and synchronised $3 \mathrm{kHz}$ leakage current waveform recorder, and a 15 frame per second video recorder monitor sample activity over the test duration. The data logger records: accumulated charge, and maximum/minimum current and voltage for every minute period of the test. The 15 sample per second recorder continuously logs leakage current magnitude and sample voltage for the entire six hours of a test.

This system gives the opportunity to analyse the electrical performance of different materials, and three different formulations of commercially produced SIR have been tested. Materials B and C are currently used as HVac outdoor insulation. Material A is a variation of B with an increased electrical conductivity. Material A is anticipated to gather less surface charge, increase dc electric field uniformity, and be more suited to HVdc applications.

The dielectric sample under test is placed on a 45 degree angle and a contaminant made from deionised water, ammonium chloride and soaping agent Triton X-100 (isooctylphenoxypolyethoxyethanol) drips down the underside of the sample between two electrodes, as in Figure 1. The liquid emerges from a quill hole in the top electrode and the bottom electrode has a series of teeth to permit the passage of contaminant without a damming effect [9].The contaminant according to IEC 60587 has a conductivity of $2532 \mu \mathrm{S} / \mathrm{cm}$. A voltage is applied to the top electrode from which the contaminant emerges. Flow rates of 150,225 and $300 \mu \mathrm{l} / \mathrm{min}$ are used for $2.25,2.7$ and 3.15 $\mathrm{kV} \mathrm{dc}$ respectively, rates also taken from IEC 60587. 


\section{TRACKING AND EROSION PROCESSES}

\subsection{ELECTRICAL DISCHARGES}

Bridging of the two electrodes with a filament of moisture results in conduction and Joule heating of the contaminant on the surface. While Joule heating from the contaminant will result in a slow increase in average surface temperature, discharges produce very rapid localised heating. This gives rise to a system with three possible states:

1. A continuous conductive filament forms on the surface and conduction and Joule heating take place.

2. A dry band forms in the conductive filament and the gap is bridged by an arc. This arc will remain on the surface until:

a) The contaminant quenches the arc, returning to stage 1

b) The arc is non-sustainable and is extinguished

3. With an arc-free dry-band formed, a non conductive state remains until the reconnection of a continuous conductive filament. This could happen in two ways:

a) Contaminant on the surface bridges the gap, bringing the surface back to stage 1 .

b) An arc re-strikes, bringing the surface back to stage 2 In a tracking test these states can occur for varying durations and currents in stages 2 and 3 have varying magnitudes.

\subsection{CONDITIONS FOR DAMAGE}

In state 2 , the nature of the arc and damage caused is governed by the material surface properties, surface condition and contaminant distribution. When enough thermal energy is transferred from the arc to the SIR surface, deep erosive material decomposition will take place. This results in mass loss from the sample and the formation of a silica-like char in its place. It is anticipated that there are three conditions under which we may find deep erosion:

a) Stable arcing - a continuous flow of contaminant streams to the arcing point. The path between the arc and the electrodes remains wet and conductive. The channel of contaminant is confined somewhat by the surface of the SIR.

b) High temperature arcing - there is a high magnitude of leakage current and the arc power is large.

c) Efficient arcing - arcs strike physically close to the surface or discharges occur under existing char, which increases the efficiency of heat transfer from the arc to the material surface.

Other chemical processes resulting from the arc such as UV radiation, the formation of ozone and various nitric acids may also play a part in material degradation. Understanding such processes is a necessary step towards building a picture of material degradation in service.

\section{MATERIAL AND POLARITY COMPARISON}

Figure 2 shows the pattern of degradation on typical samples after testing for 40 minutes and almost 6 hours. After 40 minutes all samples show damage due to surface discharges. The damage at $3.15 \mathrm{kV}$ dc is more widespread than the thin line which is developed under $2.25 \mathrm{kV}$ dc. Even at this early stage in a test the patterns of damage under each polarity are different. In positive tests a) and b), a continuous, flat and solid hydrophilic line has formed between the electrodes, whereas in the negative cases c) and d), the track is more predominant in the bottom half of the sample. In $-2.25 \mathrm{kV}$ dc tests, a foam forms around the negative electrode tip, which maybe the result of contaminant boiling under Joule heating, but is more likely to be the formation of hydrogen gas as a by-product of electrolysis.

At the end of the test under positive conditions, the solid hydrophilic layer formed between the electrodes is considerably wider than at 40 minutes. However, under negative conditions, this solid layer still only reaches approximately half way up the sample. The charred region which can be seen in both the $3.15 \mathrm{kV}$ dc tests formed from the grounded, bottom electrode and grew upwards and outwards, however, the result is a very different shaped charred region in each case. The principle difference being the extension up to the top electrode in the positive case.

In Figure 3a, histogram bars show the average cumulative charge for five tests that were conducted under each condition and for each material formulation. The error bars show the maximum and minimum values from these five tests. Cumulative charge is taken to be the integration of the leakage current for the duration of the test:

$$
\sum Q_{m}=\int_{0}^{6 \text { hours }} I d t
$$

Cumulative charge is a measure of how much charge is passed when the sample is conductive. This includes periods of high current when no arc is present (i.e. the sample is in stage 1). As a result it is difficult to use cumulative charge as a measure of contribution to damage. However, it does show whether different material properties have had a notable effect on the nature of test.

The measurements of mass loss and erosion depth give consistent results. Of the four test conditions shown in Figure $3 \mathrm{c}$ and $\mathrm{d},+3.15 \mathrm{kV}$ is the most damaging to all three materials. This is followed by $-3.15 \mathrm{kV}$ and $+2.25 \mathrm{kV}$, which have similar results, and the lowest measured levels of degradation occur under $-2.25 \mathrm{kV}$. Also, positive dc is more damaging than its negative equivalent. The reasons for this are investigated through the leakage currents in section 5. The measurements of peak current observed during a test, shown in Figure $2 b$, are indicative of the observed physical mass loss and erosion depth. This could be because higher leakage currents cause increased degradation, and also 


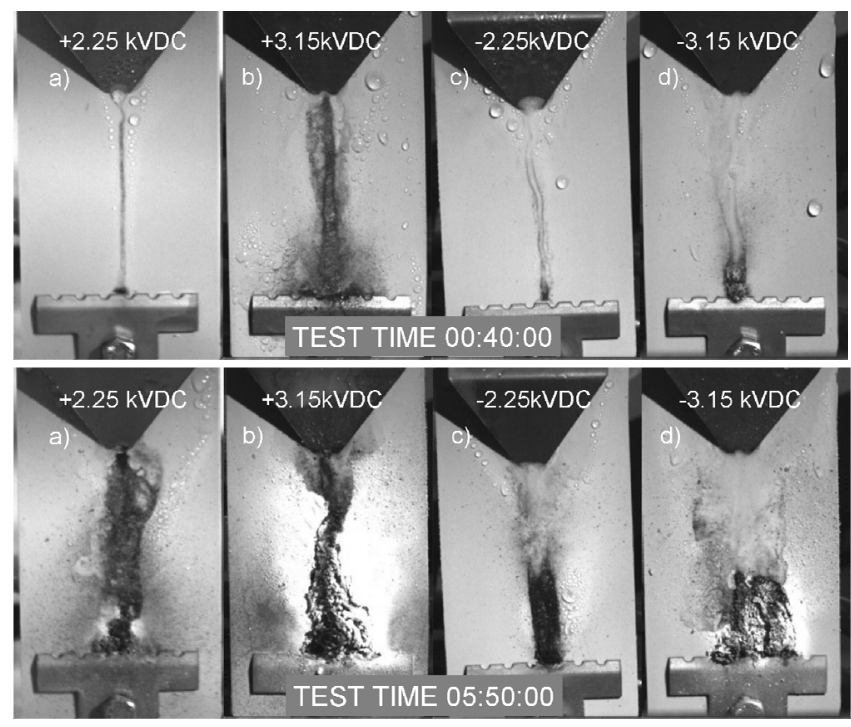

Figure 2. Condition of material A after: top picture 40 minutes and bottom picture 5 hours 50 minutes, where a) +2.25 b) +3.15 c) -2.25 d) -3.15 $\mathrm{kVDC}$ tests

because as the material is degraded the dielectric material surface can facilitate higher surface currents. The measurement of total accumulated charge over the test is highest under negative test conditions, despite the fact that less physical damage is observed in the negative cases.

In the most severe test condition of $+3.15 \mathrm{kVDC}$, material $\mathrm{C}$ has the highest resistance to tracking and erosion. From Figure $3 \mathrm{c}$ and $\mathrm{d}$ this is indicated by a significantly lower mass loss and erosion depth than the other materials. On average, material $\mathrm{C}$ passes a similar amount of charge and exhibits the lowest average maximum current, albeit similar to A. At $2.25 \mathrm{kV}$ test levels, material $\mathrm{C}$ performs similarly to the other materials.

Under negative dc tests, material $\mathrm{C}$ exhibits a whitening of the surface as the result of surface discharges, which is not as visible on the other two materials. It is anticipated that this is due to difference in material formulation, information concerning which is not available.

In $2.25 \mathrm{kV}$ tests, the cumulative charge appears correlated to the maximum erosion depth, however, in $3.5 \mathrm{kV}$ tests this would appear not to be so. The samples with the highest maximum current however do have the greatest degree of damage.

\subsection{ELECTRODE EROSION}

During both ac and dc tracking tests, electrodes can become significantly eroded such that they are unsuitable for use in further tests [10]. For this reason they are only used once. In the dc tests, one electrode erodes significantly more than the other, and the polarity of the dc voltage dictates whether this is the top or bottom electrode. In positive tests, the top positive electrode is more eroded, whereas in negative tests the bottom grounded electrode is more eroded. Figure 4 shows pictures of such electrode erosion after $6 \mathrm{~h}$ of testing at $2.7 \mathrm{kV}$ dc. In Figure $4 \mathrm{~b}$, there is also a solid dark layer which has built up on the bottom electrode.
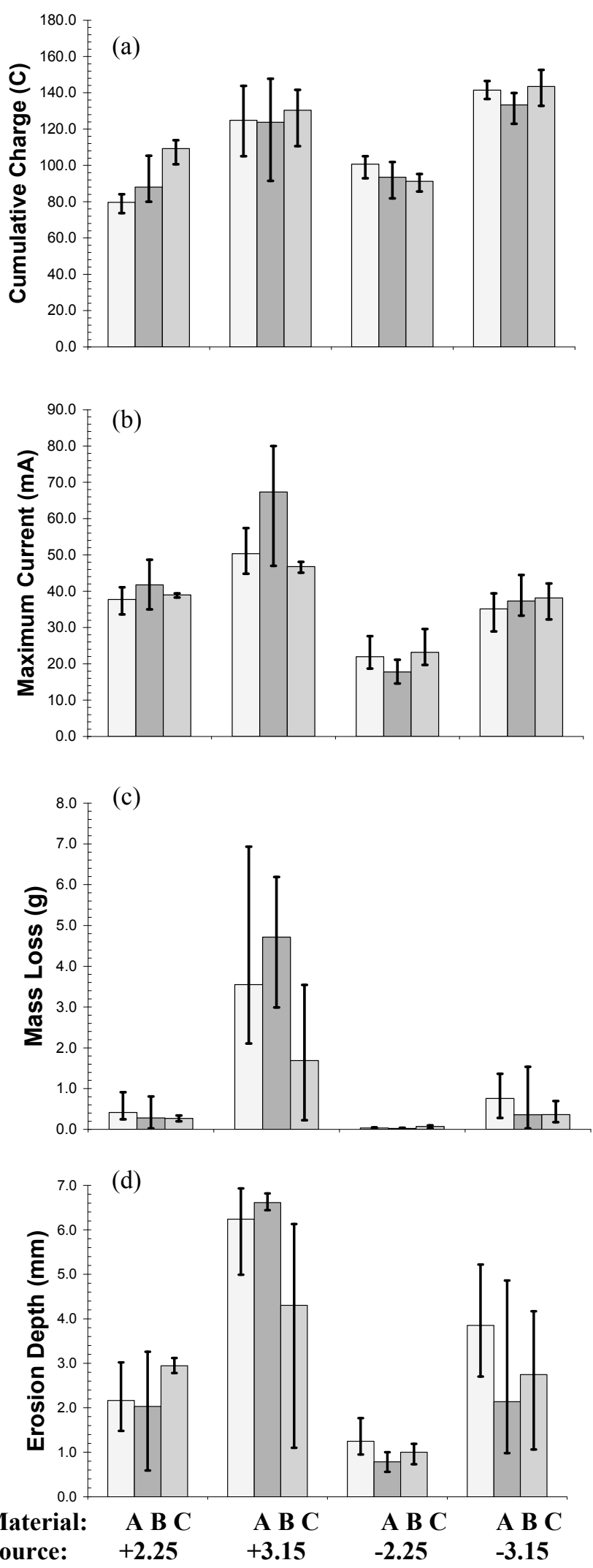

Figure 3. Results for $+2.25,+3.15,-2.25$ and $-3.15 \mathrm{kV}$ dc tests with materials $\mathrm{A}, \mathrm{B}$ and $\mathrm{C}$. 

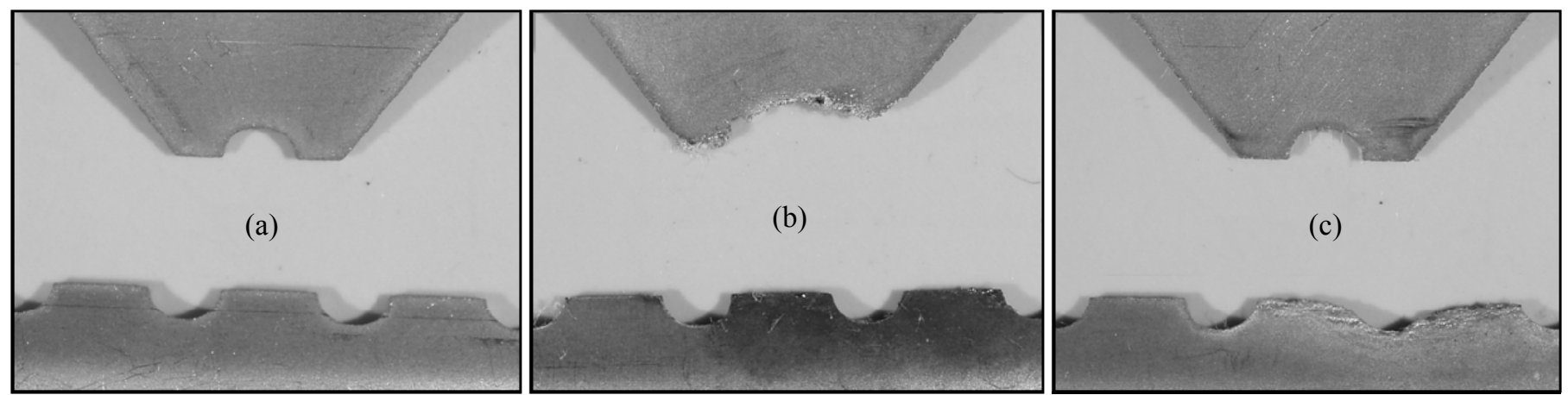

Figure 4. Pictures of quill hole of top electrodes (energised) and the middle-section of bottom (grounded) electrodes a) before testing b) after a 6 hour $+2.7 \mathrm{kV}$ dc test and c) after a 6 hour $-2.7 \mathrm{kV}$ dc test; picture widths are $18 \mathrm{~mm}$

The difference in electrode mass was measured before and after testing for the tests presented in the previous section; these data are shown in Figure 5. In positive tests, electrode mass loss of 10 to $35 \mathrm{mg}$ has been measured at the top (energised) electrode, whereas the negative electrode shows an increase in electrode mass and formation of a solid dark layer as can be seen in Figure 4b. This mass increase varies between individual tests and is most likely due to oxidation of the stainless steel electrodes as a result of high temperature arcing. In the negative case, erosion occurs at the bottom electrode, yet the mass of the top electrode does not exhibit any change. The formation of a solid dark layer on the top electrode has not been observed in any negative tests.
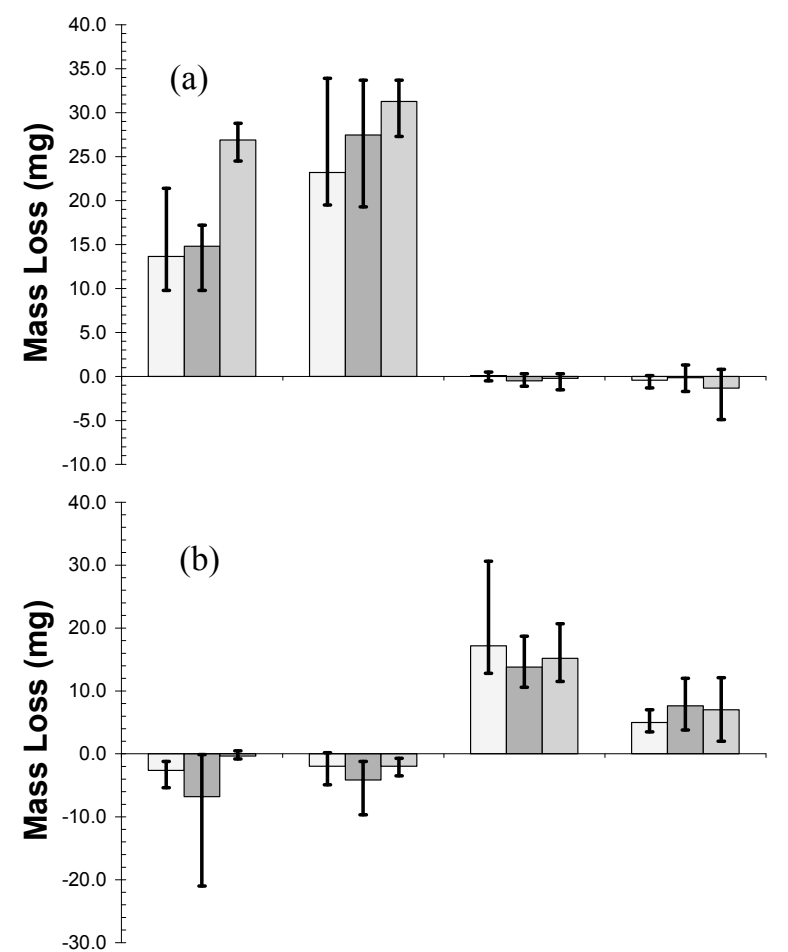
Material:
A B C
A B C
A B C
A B C
Source:
$+2.25+3.15$
$-2.25$
$-3.15$

Figure 5. a) mass loss from top (energised) electrode b) mass loss from bottom (grounded) electrode. Negative mass loss implies mass gain.
Given that the electrodes used are allowing a current to pass through an ionic solution, it is reasonable to assume the erosion process is due to electrolysis. If electrolysis is taking place, the mass of electrode liberated should be proportional to the total charge passed. In Figure $6 \mathrm{a}$, the trend line shows, this is clearly the case on the top electrode under positive dc.

In Figure 3a, the cumulative charge for $-3.15 \mathrm{kV}$ dc is significantly greater than $-2.25 \mathrm{kV}$ dc. The resultant electrode mass loss due to electrolysis should therefore be higher. However, Figure 5b shows, the recorded bottom electrode mass loss at $-3.15 \mathrm{kV}$ dc is lower than at $2.25 \mathrm{kVdc}$. This reduction is due to electrode oxidation at
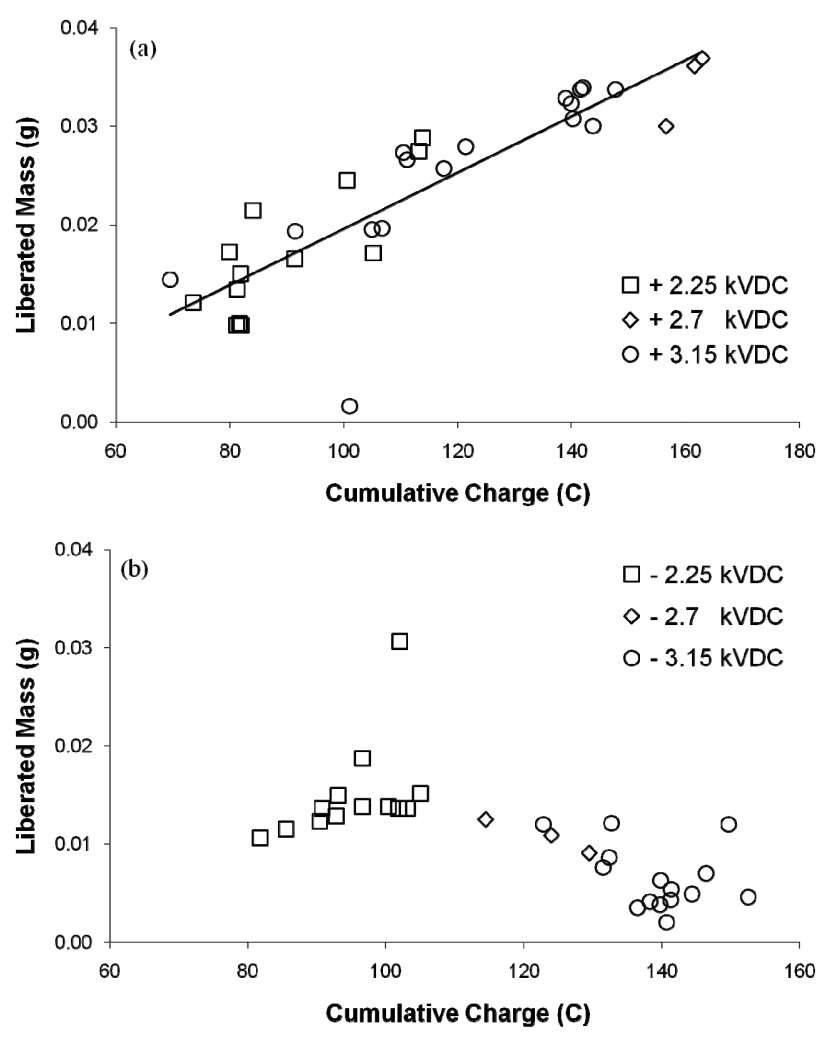

Figure 6. Cumulative charge versus liberated HV electrode mass for a) top electrode in positive tests and b) bottom electrode in negative tests with all materials shown 


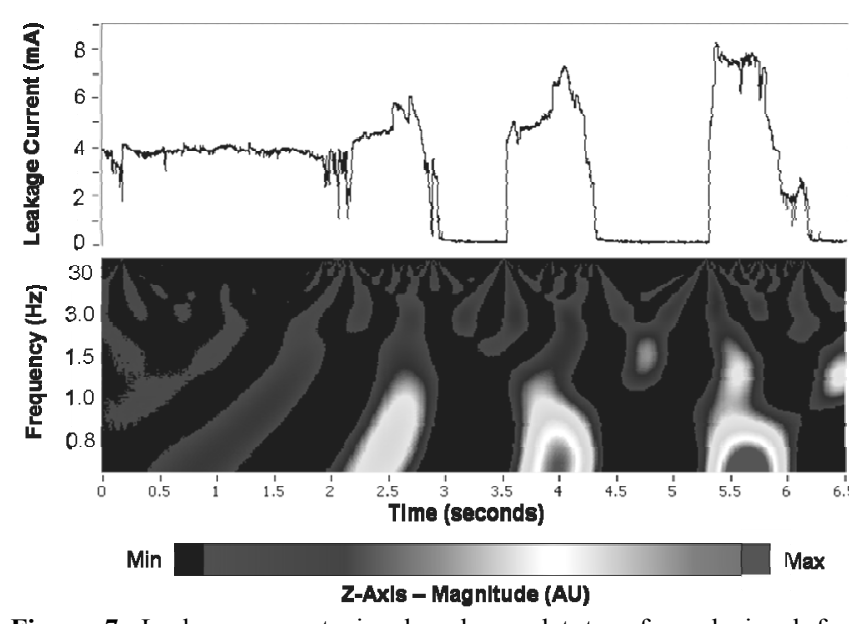

Figure 7. Leakage current signal and wavelet transformed signal for $+2.25 \mathrm{kVDC}$ test after 20 mins on material A

locations where deep erosion of the SIR has taken place; this is not seen under $-2.25 \mathrm{kV}$ dc. As a result, the trend in Figure $6 \mathrm{~b}$ does not follow for electrode mass loss under negative conditions on the bottom electrode.

The process of liberating metallic species from the top electrode in the positive case, may add to the conductivity of the contaminant filament. This would explain the increase in average current under positive conditions, and has been reported in similar de tests on glass surfaces [11].

\subsection{LEAKAGE CURRENT ANALYSIS METHODOLOGY}

By examining the nature of leakage current, the precursors of material damage may be evaluated. In particular the time-distribution of current magnitude can be assessed using the 15 sample per second recorder, which is an effective way to observe the low frequency surface behaviour. This information can then be presented as a measure of intermittency; a measure of the amount of time a sample spends in a non-conducting state during a test. A histogram of the distribution of current magnitude shows how the sample behaves when it is conductive. Average leakage current magnitude when the sample is in a conductive state can also be obtained from this data. This is different to calculating average current from the whole test and gives information directly relating to the surface when it is in state 2 or 3 ; a conducting filament with or without a discharge present. Figure 7 shows leakage current can also be analysed in the time-frequency domain using the wavelet transform. This allows the separation of long-term (low frequency) phenomena from the more dynamic aspects of the leakage current; the findings of which are to be presented in a future paper.

Inspection of synchronised video and leakage current traces has revealed that leakage current magnitudes with an arc present or with just a conductive filament are not readily distinguishable without the video evidence: As the arc is in series with the contaminant filament the arc makes little difference to the current magnitude. The arc damages the surface by rapid localized heating, and surface temperature determines which degradation processes will take place, for example, decomposition of the ATH or decomposition of the base polymer at higher temperatures. The associated changes in the properties of the material surface may facilitate higher surface currents and so a cycle of increasing degradation evolves. It can be seen from Figure $2 \mathrm{~b}$ that the maximum current observed throughout the test is considerably higher under positive conditions than it is for negative. This suggests that the potential arc temperature is higher, and we could expect higher levels of damage based on the principle that higher temperatures are being experienced on the sample surface.

Leakage current intermittency is a measure of the time the dielectric surface spends in a non-conductive state as a percentage of the 6 hour test. It is not immediately obvious what this signifies in terms of damage. When the sample is in a conductive state it may be with or without a discharge; it could be expected that the intermittency is related to the ratio of these states. For example, when the intermittency is $0 \%$ because the contaminant flow rate far exceeds the rate of evaporation, one may expect no dry-bands to form and therefore no damage due to discharges should occur. At the other extreme, with low contaminant flow when intermittency is extremely high, arcs do not have sufficient current to cause damage or allow the arcs to become stable. This suggests there is an optimum flow rate for maximum damage in a particular test condition. Traditionally, this is considered to be when the evaporation rate is equal to the flow rate and a stable arc occurs.

\section{CASE STUDY}

As a case study, the differences between positive and negative polarity single tests on material $\mathrm{C}$ at $\pm 2.7 \mathrm{kV}$ dc have been evaluated in detail. In addition, comparisons are made with \pm 2.25 and $\pm 3.15 \mathrm{kV}$ dc test levels on the same material.

\subsection{TEST STATISTICS}

The results in Table 1 show that typical positive de tests give a higher peak leakage current (LC) and greater depth of erosion and eroded mass than negative dc at the same voltage magnitude. In addition, the positive tests have higher average leakage current. The leakage current is consistently more intermittent in nature in the positive case, but the total charge which is passed in a test does not show an obvious polarity effect.

Table 1. Test statistics for a typical test on material C

\begin{tabular}{|c|c|c|c|c|c|c|c|}
\hline Test Level & $\begin{array}{c}\text { Avg. } \\
\text { LC } \\
(\mathrm{mA})\end{array}$ & $\begin{array}{c}\text { Peak } \\
\text { LC } \\
(\mathrm{mA})\end{array}$ & $\begin{array}{c}\text { Intermi } \\
\text { tency } \\
(\%)\end{array}$ & $\begin{array}{c}\Sigma Q_{\mathrm{m}} \\
(\mathrm{C})\end{array}$ & $\begin{array}{c}\Sigma Q_{\mathrm{c}} \\
(\mathrm{C})\end{array}$ & $\begin{array}{c}\text { Erosion } \\
\text { Depth } \\
(\mathrm{mm})\end{array}$ & $\begin{array}{c}\text { Mass } \\
\text { Loss } \\
(\mathrm{g})\end{array}$ \\
\hline$+2.7 \mathrm{kVDC}$ & 12.1 & 35 & 29 & 162 & 185 & 4.6 & 1.2 \\
\hline$-2.7 \mathrm{kVDC}$ & 5.5 & 24 & 19 & 115 & 97 & 2.0 & 0.2 \\
\hline$+3.15 \mathrm{kVDC}$ & 14.1 & 45 & 42 & 111 & 129 & 5.6 & 1.3 \\
\hline$-3.15 \mathrm{kVDC}$ & 7.2 & 32 & 16 & 150 & 130 & 2.4 & 0.2 \\
\hline$+2.25 \mathrm{kVDC}$ & 9.1 & 39 & 36 & 114 & 130 & 2.9 & 0.3 \\
\hline$-2.25 \mathrm{kVDC}$ & 4.4 & 20 & 12 & 95 & 83 & 0.7 & 0.03 \\
\hline
\end{tabular}


As the contaminant flow rate and series resistance are increased when the test voltage is increased, the average current increases in both polarities. This increase in average leakage current would suggest a more severe test, which is reflected in the erosion depth and mass loss. The values of peak current, intermittency and cumulative charge however do not follow this trend. This suggests that the process by which discharges are stabilised or extinguished and so cause erosion may differ.

If the percentage increase in average leakage current from negative to positive tests is compared by dividing positive leakage current by that of negative, for $2.7,3.15$ and $2.25 \mathrm{kV}$ dc the outcome is $120 \%, 96 \%$ and $107 \%$, respectively. This similarity suggests consistency in the polarity dependant effects at each test level. To investigate this further, the effect of $\mathrm{HV}$ and $\mathrm{LV}$ electrode reversal are considered in section 6.1.

The cumulative charge $\Sigma Q_{m}$ is a measure of electrical charge that is passed by the sample in a test. In the test measurement system it is measured by taking an integration of the current signal over the $6 \mathrm{~h}$ of the test. It may also be estimated by multiplying the average LC when the sample is conducting by the amount of time the sample is in a conductive state as:

$$
\sum Q_{c} \approx \overline{L C} \times(1-\text { Intermittency }) \times \text { TestTime }
$$

The estimated cumulative charge $\Sigma \mathrm{Q}_{\mathrm{c}}$ from equation (3) is $14 \%$ to $16 \%$ greater than the measured value $\Sigma Q_{m}$ in positive tests, and $13 \%$ to $15 \%$ lower for negative tests. This may then be a useful way of estimating aggregate charge when full instrumentation is not available.

\subsection{CUMULATIVE CHARGE}

Figure 8 shows that the magnitude of the accumulated charge per minute is higher in the positive case over the duration of the test, despite intermittency being $10 \%$ greater than the negative case. This is because positive average current is 2 times greater, and from equation 3 this would be the expected overall effect. In the first hour of the test, accumulated charge per minute increases rapidly, as this is the period when the sample surface is being conditioned by the discharges. By $1 \mathrm{~h}$, the pattern of surface damage looks quite different for each polarity. This raises the question of whether it is the surface degradation which dictates the leakage current, or the leakage current which controls the surface degradation pattern. This is investigated further in section 8.2 where polarity is changed three hours into a test.

Between 1 to $3 \mathrm{~h}$, the accumulated charge per minute increases steadily as the surface becomes more degraded. From 3-6 h under negative conditions there is no significant change in the rate of accumulated charge, however, in the positive case, there is a transition at the three hour point where the rate increases by $0.1 \mathrm{C} /$ minute. This occurs at the onset of deep erosion in the test, where the formation of char on the surface allows a larger volume of contaminant to be retained at any one time. The result is often higher peak currents and more damaging discharges. The char on the surface can also change the path in which the contaminant flows, which may cause periods of nonconduction as happens at 3 hour 40 minutes in the positive test shown.

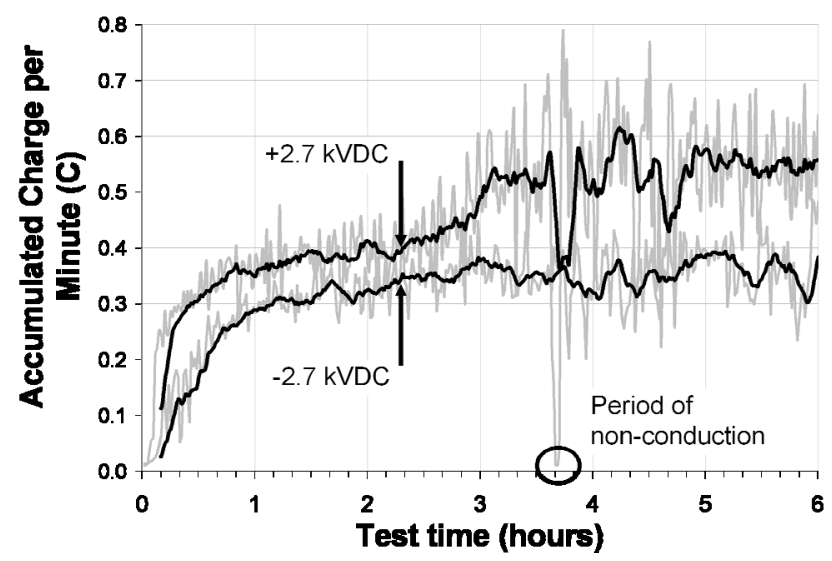

Figure 8. Moving average of 10 of accumulated charge per minute for material $\mathrm{C}$ in a positive and negative polarity $2.7 \mathrm{kV}$ dc test

\subsection{INTERMITTENCY AND AVERAGE LEAKAGE CURRENT}

Intermittency has been quantified by finding the ratio of times when the leakage current is below and above $1 \mathrm{~mA}$. Intermittency may be regarded as the percentage of the test duration that the sample surface is 'non-conductive'. This is distinctly different in the positive and negative cases. The figures from $2.7 \mathrm{kV}$ dc in Table 1 show, the sample surface is non-conductive for $29 \%$ of the time under positive conditions, and $19 \%$ of the time for negative conditions. Considering that the contaminant flow rate is constant and assuming that all contaminant is evaporated, this suggests that the rate of evaporation under positive conditions is much higher. The rate of evaporation being higher is also consistent with the average surface current being higher. Possible contributing factors to this are the conductivity of the contaminant being affected by electrolysis, the contaminant filament having greater/smaller cross sectional area due to the geometry of the aged surface, or polarity dependence in the electro-hydrodynamic behaviour of the contaminant.

As in the accumulated charge plot, Figure 9a shows a rise in average leakage current at $3 \mathrm{~h}$ (180 minutes) in the $+2.7 \mathrm{kV}$ test. After the onset of deep erosion, the intermittency begins to vary as the sample alternates between non conductive and highly conductive states. After 5 hours 20 minutes (320 minutes) there is a 2 milliamp rise in average current and a $20 \%$ increase in intermittency. Observed video images at this time, does not show if this particular condition gave any increased rate of damage. Because the increase in current was met by an increase in intermittency, the accumulated charge for this period remains fairly constant. In the $-2.7 \mathrm{kV}$ dc test, the average current is smaller in magnitude, but is also remarkably stable over the course of the test. The intermittency is also lower than the positive case, and there are a number of 
periods when the intermittency reduces to zero. Synchronised current and video images at 3 and 5 hours into the test, show stable arcs, and these are perhaps the most damaging periods in the test.

\subsection{LEAKAGE CURRENT DISTRIBUTION}

The leakage current distribution has been analysed by sampling the current magnitude at a rate of 15 samples per second and plotting the information in a histogram with a bin range of $1 \mathrm{~mA}$. In

Figure 10, the first column $(<1 \mathrm{~mA})$ shows the percentage of recorded discharges where the sample surface was nonconducting; this is the measure of intermittency. When the sample is conducting, the distribution of leakage current magnitude follows a normal distribution. It is envisaged that the current follows a normal distribution because there are a large number of factors which contribute to its overall nature.

\subsection{BOX AND WHISKER PLOTS}

In Figure 11, the distribution of the leakage current magnitude has been calculated in each hour of the test. This is shown as a box and whisker plot, which identifies the:

1. Minimum current in that hour

2. Mean minus the standard deviation

3 . Average current for that hour

4. Mean plus the standard deviation

5. Maximum current in that hour
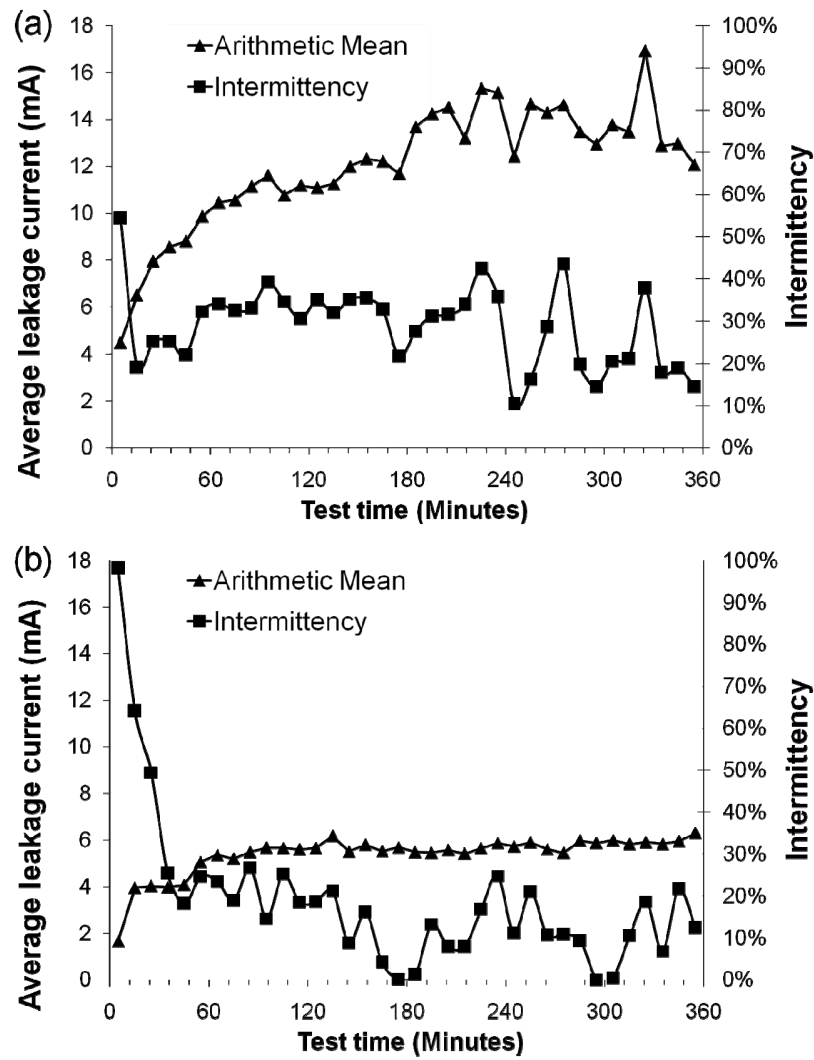

Figure 9. Intermittency (\%) and average current $(\mathrm{mA})$ in 10 minute intervals for (a) $+2.7 \mathrm{kVDC}$ (b) $-2.7 \mathrm{kV}$ dc on material C.
It shows that the maximum and average leakage current in each hour of the test are greater under positive conditions, yet the ratio of maximum to mean current is much lower in the positive case. This ratio is a further behavioural difference between positive and negative conditions. The same result is also observed in the 2.25 and $3.15 \mathrm{kV} \mathrm{dc}$ tests.

\section{IMPACT OF POLARITY REVERSAL}

In order to investigate some of the phenomena which have been observed during the standardised test, two further types of tests were introduced: reversal of electrode potential, and reversing polarity mid-way through a test.

\subsection{REVERSED POTENTIAL TESTS}

In the following 'reversed potential' tests, the bottom electrode is energised and the top electrode is grounded as depicted in Figure 12. The effect of this is that the potential across the sample is opposite polarity and equivalent to the standard opposite polarity test, however, the potential with respect to external objects is changed. Results are presented from single $2.7 \mathrm{kV}$ dc tests on material A.
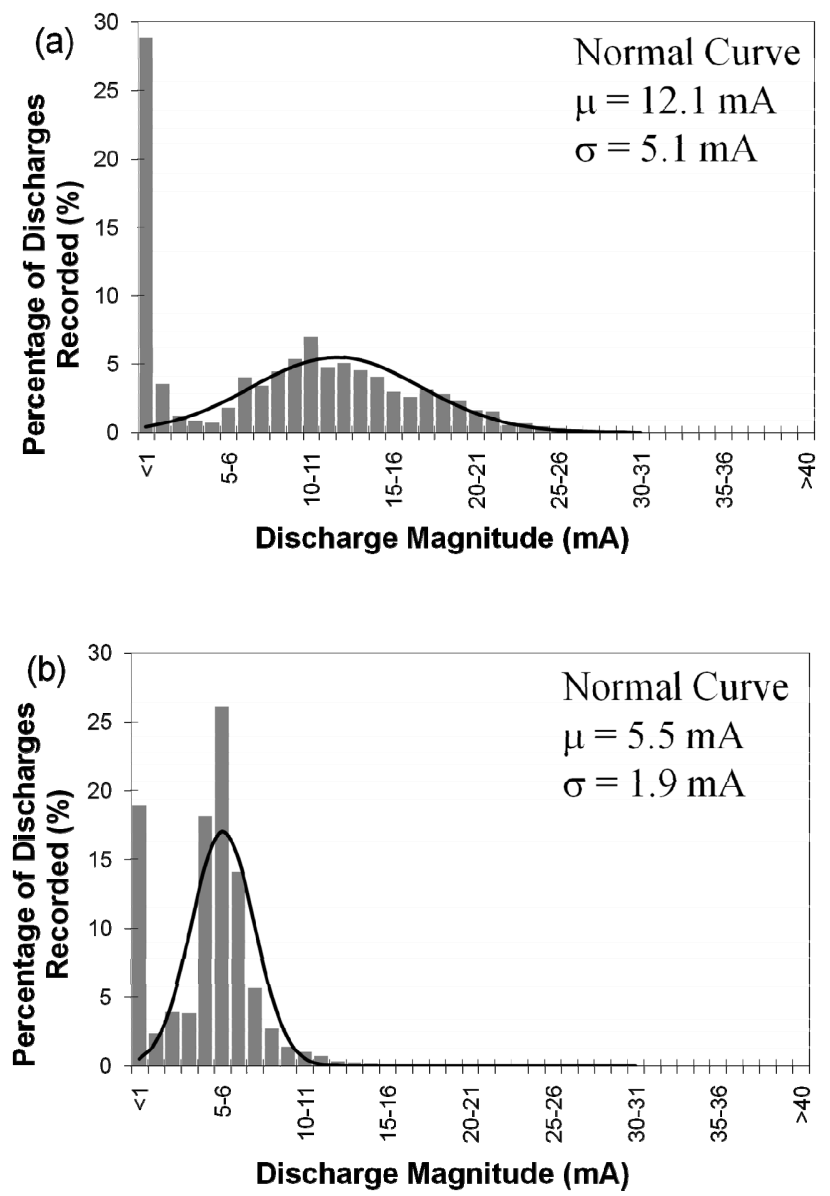

Figure 10. Histogram of leakage current magnitude for (a) $+2.7 \mathrm{kV}$, and (b) $-2.7 \mathrm{kV}$ on material C. Best fit normal distributions are shown and mean $(\mu)$ and standard deviation given $(\sigma)$ 

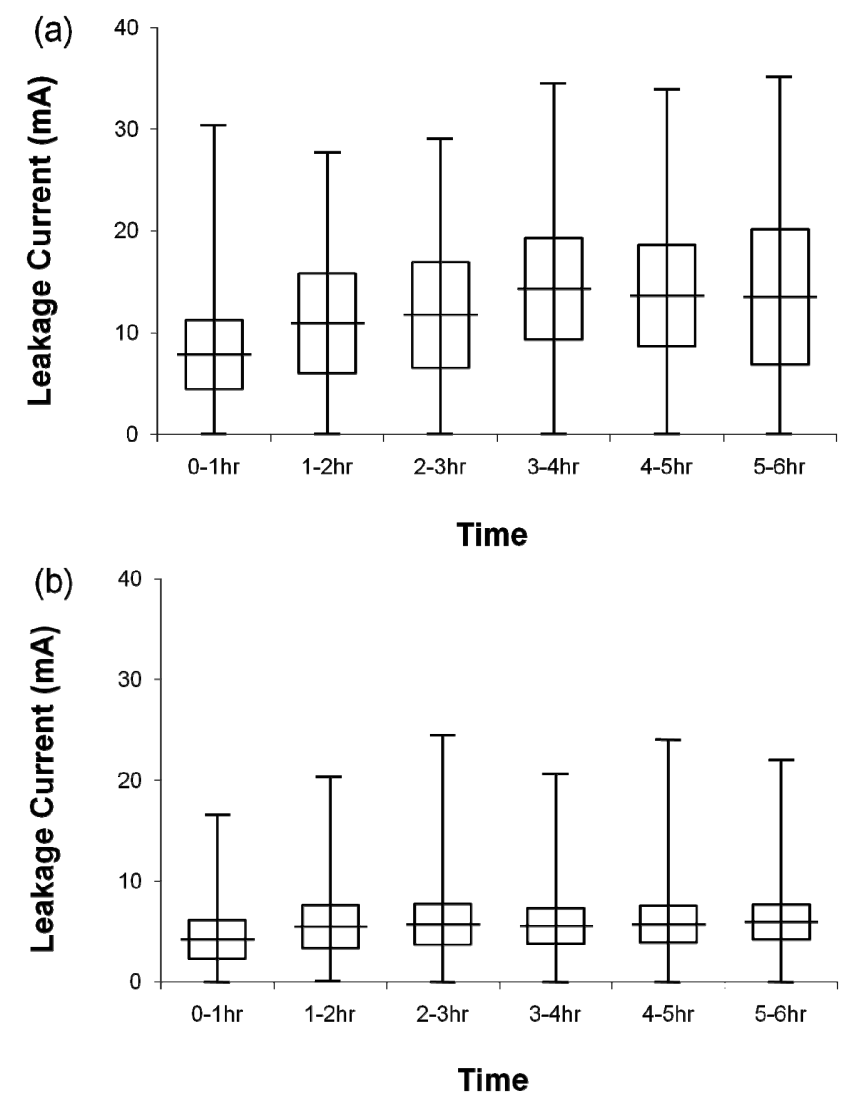

Figure 11. Box and whisker plots for each hour of the test (a) $+2.7 \mathrm{kV} \mathrm{dc}$ and (b) $-2.7 \mathrm{KV}$ dc on material $\mathrm{C}$.

Referring to the results in Table 2, when the electrodes potentials were reversed the negative reversed potential test looked more like the positive test, and vice-versa as might be expected. Electrode erosion due to electrolysis always occurs on the electrode which is at the higher potential (anode), and the average current is again highest when it is the top electrode is being eroded. Although average leakage currents remain comparable, the intermittency is greatly reduced in both cases when the electrodes are reversed. This suggests that there are other factors affecting the test aside from the increase in average leakage current, such as the electric field with relation to the surrounding environment.

In the case study in Section 5, it was highlighted that the ratio between positive and negative average leakage current was similar for each test level. This suggested that the difference is directly attributable to the polarity of the HV electrode. In the standard tests shown in Table 2 the increase between positive and negative average leakage current was $123 \%$, $(12.7 \mathrm{~mA}$ divided by $5.7 \mathrm{~mA})$ which is the same as reported in Section 5 on material $C$. The percentage increase for the reversed potential tests however is only $73 \%(12.1 \mathrm{~mA}$ divided by $7.0 \mathrm{~mA})$, and there are many further differences in the test statistics. Both reversed polarity tests show reduced erosion depth and sample mass loss as compared to the standard tests. They also have considerably reduced peak current and intermittency, however, the cumulative charge is greater in both cases.

In section 5.1, the estimated cumulative charge $\Sigma Q_{c}$ was compared with the measured values $\Sigma \mathrm{Q}_{\mathrm{m}}$. The result was an estimated cumulative charge $14 \%$ to $16 \%$ greater than the measured value in positive tests, and $13 \%$ to $15 \%$ lower for negative tests. The material A test results were $+12 \%$ and $17 \%$ respectively. However, in the reversed potential tests, $-2.7 \mathrm{kV}$ dc showed an estimated value $9.5 \%$ lower than that of the measured, and in the positive test a $9.1 \%$ higher. Despite the $-2.7 \mathrm{kV}$ dc reversed potential test looking like the positive $2.7 \mathrm{kV}$ dc normal test, the estimated cumulative charge is an under estimation, and vice-versa.

Figure 13 highlights the differences in leakage current distribution between (a) the regular $+2.7 \mathrm{kV}$ dc test and (b) the reversed potential negative test. Uniquely, for the whole of the sixth hour of the reversed polarity test, the minimum current exceeds $1 \mathrm{~mA}$. To examine this in more detail Figure 14a shows the positive test in the presence of deep erosion. High current peaks, in this case up to $42 \mathrm{~mA}$, and a high level of intermittency, where evaporation rate is high and contaminant flow direction is influenced by the char on the surface. In comparison to this, Figure $14 \mathrm{~b}$ from the reversed polarity test has a comparable average current, but the peak currents are not as high, presumably because continual conduction is preventing the build up of high volumes of contaminant. Video playback from this hour shows there is a stable arc at the upper most part of the charred region. This causes elongation of the charred area as time passes.

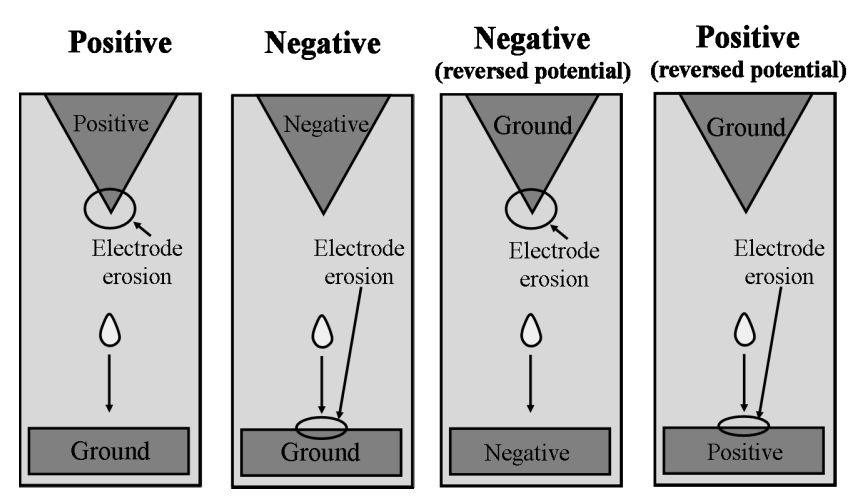

Figure 12. Electrode reversal configurations. The two cases on the left are traditional with grounded bottom electrodes, in the reversed cases on the right the upper electrodes are grounded.

Table 2. Test results for single reversed polarity tests (RP) on Material A

\begin{tabular}{|c|c|c|c|c|c|c|c|c|c|}
\hline \multirow{3}{*}{$\begin{array}{c}\text { Test Level } \\
\text { (kVDC) }\end{array}$} & \multirow{3}{*}{$\begin{array}{c}\text { Avg } \\
\text { LC } \\
(\mathrm{mA})\end{array}$} & \multirow{3}{*}{$\begin{array}{c}\text { Peak } \\
\text { LC } \\
(\mathrm{mA})\end{array}$} & \multirow{3}{*}{$\begin{array}{c}\text { Intermi } \\
\text { ttency } \\
(\%)\end{array}$} & \multirow{3}{*}{$\begin{array}{c}\Sigma Q_{\mathrm{m}} \\
(\mathrm{C})\end{array}$} & \multirow{3}{*}{$\begin{array}{l}\Sigma Q_{\mathrm{c}} \\
(\mathrm{C})\end{array}$} & \multirow{3}{*}{$\begin{array}{l}\text { Erosion } \\
\text { Depth } \\
(\mathrm{mm})\end{array}$} & \multicolumn{3}{|c|}{ Mass Loss (g) } \\
\hline & & & & & & & \multirow{2}{*}{ SIR } & \multicolumn{2}{|c|}{ Electrodes } \\
\hline & & & & & & & & Top & Bot \\
\hline+2.7 & 12.7 & 42.4 & 33 & 163 & 185 & 6.5 & 3.1 & 0.04 & 0.00 \\
\hline$-2.7 \mathrm{RP}$ & 12.1 & 27.5 & 14 & 245 & 224 & 5.4 & 2.2 & 0.07 & 0.00 \\
\hline-2.7 & 5.7 & 27.1 & 16 & 124 & 103 & 2.8 & 0.3 & 0.00 & 0.01 \\
\hline$+2.7 \mathrm{RP}$ & 7.0 & 20.9 & 6 & 131 & 143 & 1.2 & 0.1 & 0.00 & 0.03 \\
\hline
\end{tabular}



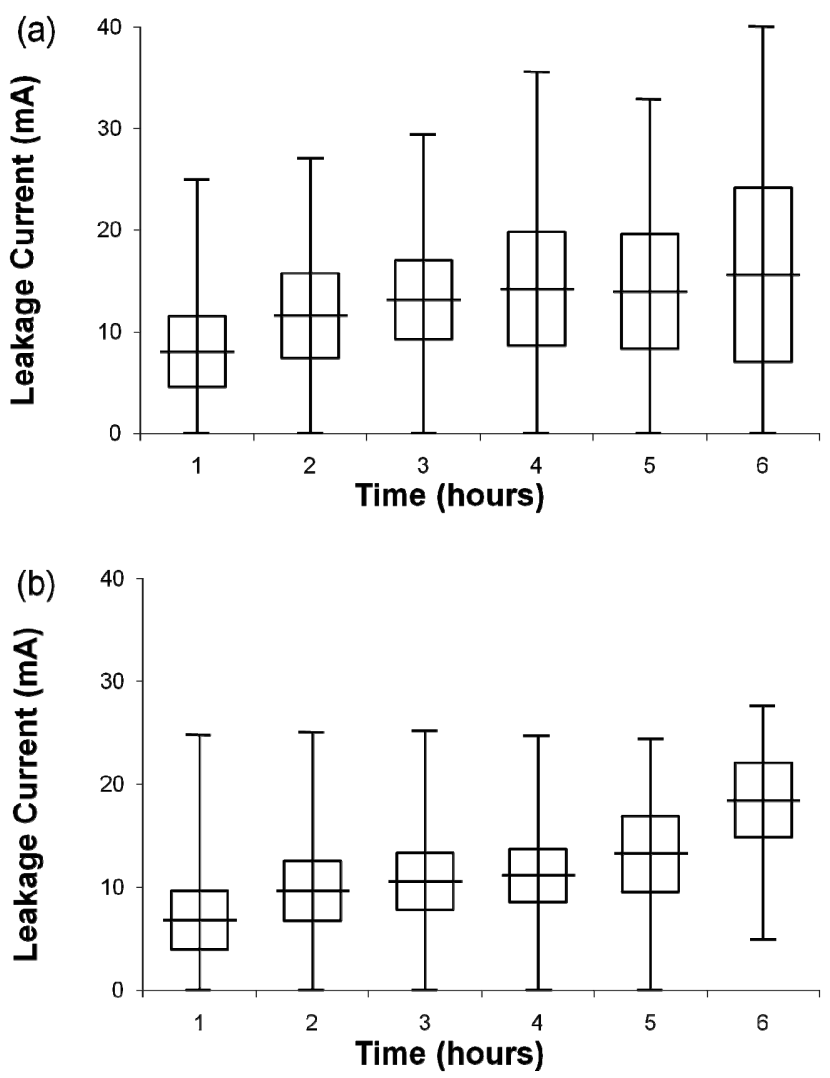

Figure 13. Box and whisker plots (a) $+2.7 \mathrm{kV}$ dc normal test and (b) -2.7 $\mathrm{kV}$ dc reversed potential test on material A.

\subsection{DUAL POLARITY TESTS}

From section 4, it was unclear if it is the surface which dictates the nature of the discharge and leakage current in the test or is it the test condition which changes the surfaces degradation pattern in each polarity. To investigate this, two tests were conducted and the polarity of the supply was reversed at the three hour point of the test. Polarity reversal took 20 minutes to achieve in which time the voltage is off but the contaminant continued to flow over the surface. The tests were conducted at $2.7 \mathrm{kV}$ dc on material $\mathrm{C}$, and the results are presented in Table 3 . Of the tests in which polarity was reversed, the greatest erosion depth and mass loss was caused in the negative to positive test. This test also had higher average and peak currents than the other reversed polarity test. Similarly, electrode mass loss and cumulative charge were very similar in each reversed polarity test.

Figure 15 shows the box and whisker plots for the dual polarity tests. The average leakage current in each half of the test is comparable to a normal test of that polarity. This shows that the surface condition does not have a profound effect on the average current magnitude. The most damage was caused in the case of negative-to-positive polarity reversal. This is because the onset of deep erosion in positive tests is typically after three hours. The eroded mass from the positive and negative-to-positive test are similar, yet the erosion depth is approximately half for the dual polarity test. Visually the pattern of deep erosion in the negative-to-positive test was similar to the $-3.15 \mathrm{kV}$ dc test. It is likely that this is due to the difference in surface degradation pattern.

These results suggest that the leakage seen in a test is largely independent of the surface degradation pattern present, but the surface degradation pattern over the first three hours may dictate the morphology of deep erosion.
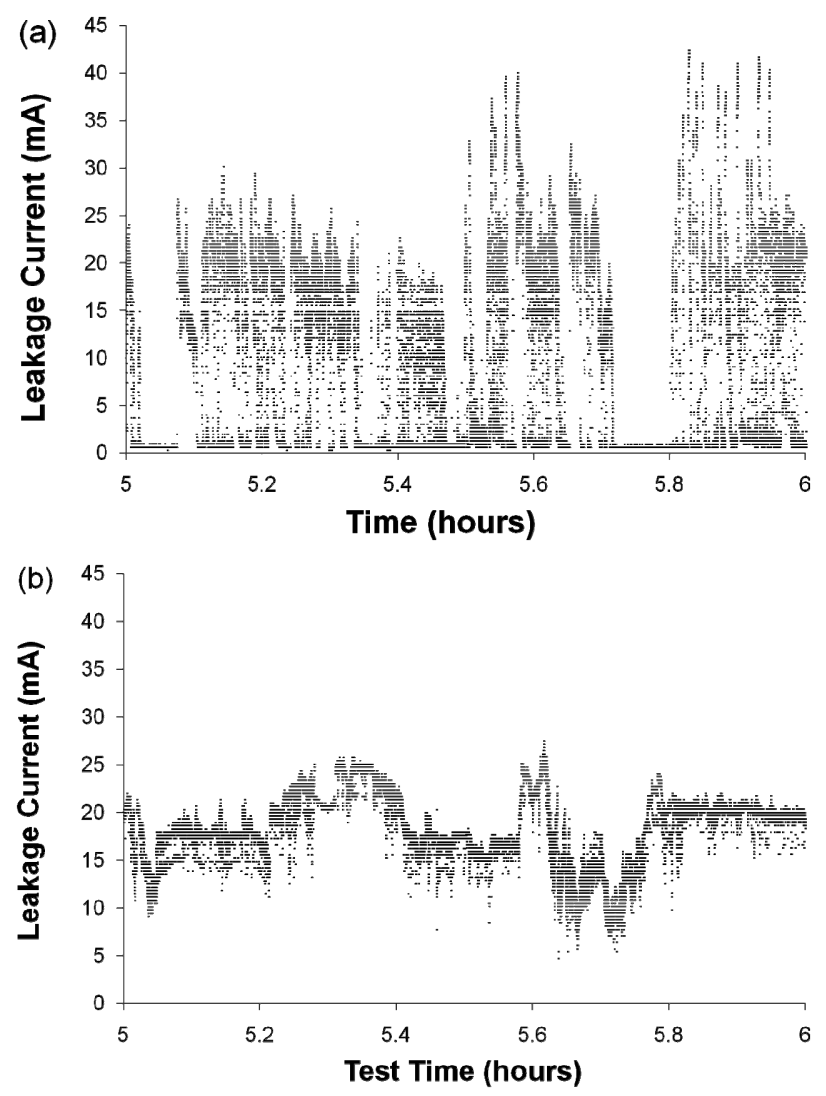

Figure 14. 15 sample per second LC waveform from 5-6 hours in a test for material A a) $+2.7 \mathrm{kV}$ dc test and b) $-2.7 \mathrm{kV}$ dc with reversed potential

Table 3. Dual polarity tests at $2.7 \mathrm{kV}$ dc on material C

\begin{tabular}{|c|c|c|c|c|c|c|c|c|c|}
\hline \multirow{3}{*}{$\begin{array}{c}\text { Test Type } \\
2.7 \\
\text { kVDC }\end{array}$} & \multirow{3}{*}{$\begin{array}{c}\text { Avg } \\
\text { LC } \\
(\mathrm{mA})\end{array}$} & \multirow{3}{*}{$\begin{array}{c}\text { Peak } \\
\text { LC } \\
(\mathrm{mA})\end{array}$} & \multirow{3}{*}{$\begin{array}{c}\text { Intermi } \\
\text { ttency } \\
(\%)\end{array}$} & \multirow{3}{*}{$\begin{array}{l}\text { Meas. } \\
\Sigma \mathrm{Q} \\
\text { (C) }\end{array}$} & \multirow{3}{*}{$\begin{array}{l}\text { Calc. } \\
\Sigma \mathrm{Q} \\
\text { (C) }\end{array}$} & \multirow{3}{*}{$\begin{array}{l}\text { Erosion } \\
\text { Depth } \\
\text { (mm) }\end{array}$} & \multicolumn{3}{|c|}{ Mass Loss (g) } \\
\hline & & & & & & & \multirow{2}{*}{ SIR } & \multicolumn{2}{|c|}{ Electrodes } \\
\hline & & & & & & & & Top & Bot \\
\hline $\begin{array}{l}\text { Neg to } \\
\text { Pos }\end{array}$ & 10.1 & 45.8 & 27 & 149 & 159 & 2.4 & 1.2 & 0.02 & 0.004 \\
\hline Pos & 12.1 & 35 & 29 & 162 & 185 & 4.6 & 1.2 & 0.04 & 0.000 \\
\hline $\begin{array}{l}\text { Pos to } \\
\text { Neg }\end{array}$ & 8.5 & 33.2 & 23 & 145 & 142 & 1.5 & 0.4 & 0.02 & 0.003 \\
\hline
\end{tabular}

\section{DISCUSSION}

This list highlights the main variables that have shown to affect the nature of the leakage current in these tests:

1 The supply voltage and hence, contaminant flow rate and series resistance according to IEC 60587

2 Surface under test

3 Existing surface condition 

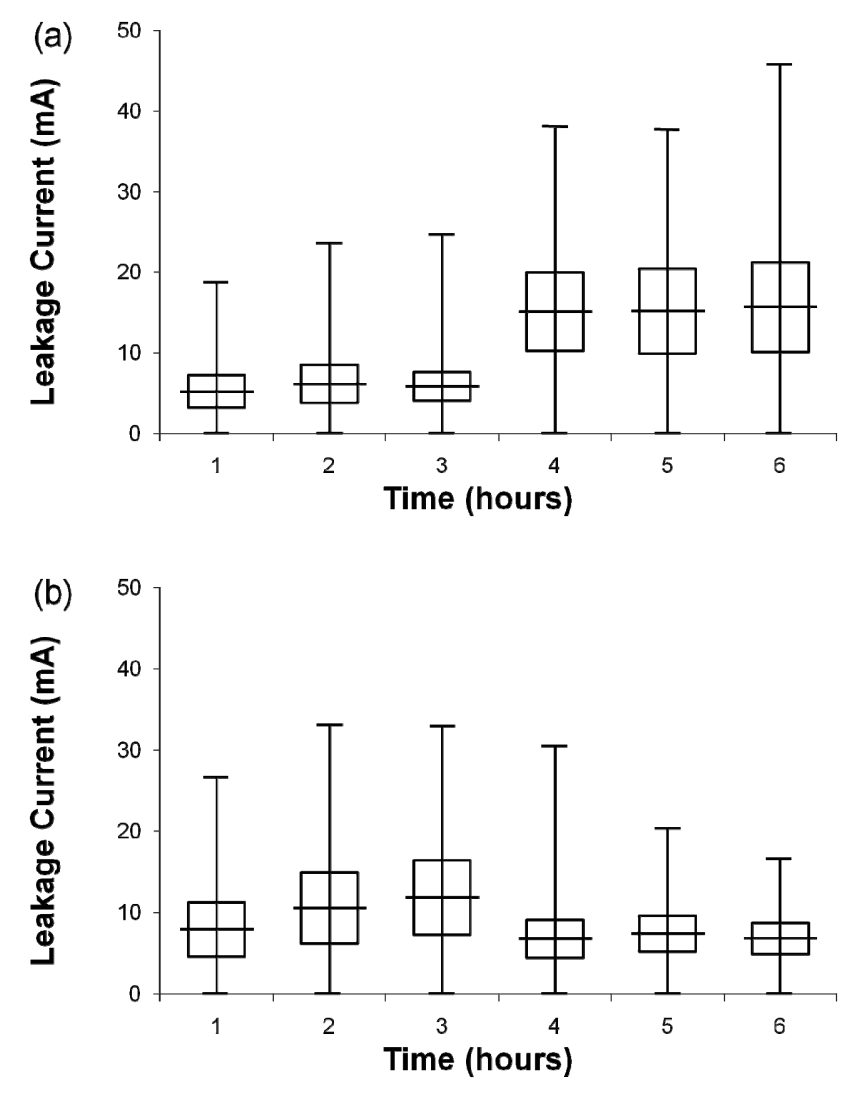

Figure 15. Box and whisker plots for (a) negative to positive (b) positive to negative dual polarity $2.7 \mathrm{kV}$ dc tests on material $\mathrm{C}$

In order to elaborate on this, the effect of changing each variable is considered in the following paragraphs. For a specific test voltage intermittency is higher under positive polarity. This suggests that the shape and volume of the contaminant filament and/or dry band arc longevity are different in each case. However, it is also possible that electrolysis, as discussed in Section 4 changes the surface and contaminant conductivity which introduces a further variable that does not happen under ac conditions.

Assuming a constant stream of contaminant, the amount of time the sample spends in a conductive state should increase with the flow rate. Once the rate of supply of contaminant surpasses the evaporation rate, the intermittency should reduce to $0 \%$. In reality, the rate of evaporation may also change with flow rate. In the knowledge that average leakage current is higher under positive conditions, it is likely that intermittency reduces to zero at a higher contaminant flow rate than under negative $\mathrm{dc}$, because the rate of evaporation is higher.

Assuming a constant conducting surface resistance, leakage current magnitude will increase linearly with supply voltage. However, it is the joule heating which increases the rate of evaporation leading to higher intermittency therefore one should consider the power dissipated in the contaminant. The evaporation rate of water, however, is a function of many additional variables.
The temperature of the water at the air-water surface, humidity and temperature of the air, and air-water surface area all play a significant role in the evaporation of the contaminant. This highlights the complexity of identifying a sole cause for the difference between polarities.

As the test voltage is increased, the specified series resistor is also increased. This limits the maximum power which can be dissipated on the surface. As the supply voltage is shared between the series resistor and the sample, maximum power is transferred to the sample when surface resistance and series resistance are equal. For this to occur, the leakage current must reach $50 \%$ of the short circuit current. For 2.25, 2.7 and $3.15 \mathrm{kV}$ dc tests this is: 103, 77 and $72 \mathrm{~mA}$ respectively. This is above the $60 \mathrm{~mA}$ failure criteria, therefore samples should always experience an increase in power dissipation when surface resistance decreases.

The shape which the contaminant takes on the surface of the SIR will change the evaporation rate. This means that the surface condition of the material is very important. The difference in the shape and extent of the aged surface is very different in the positive and negative cases, and may be the fundamental difference controlling the disparity of results in the two situations. Consider two different shapes of contaminant cross-section on the dielectric surface, which are of the same cross-sectional area: In case A, the perimeter which is open to the air and that can be evaporated is greater than case B. The situations could be compared to a hydrophobic and hydrophilic surface in the case of SIR, where case A is hydrophilic. This could potentially increase the evaporation rate, if there is sufficient heat being generated to maintain the contaminant temperature. Similarly case A has greater contact area with the solid surface and may be cooled by the thermal mass of the solid. Conversely, the bulky filament will be cooled less per unit volume by the air and the solid surface, and so may reach higher temperatures, and hence evaporate quicker. Each cross-sectional area may also influence arc longevity, and arc-root localisation. Further analysis is required to understand the thermodynamics of the two cases.

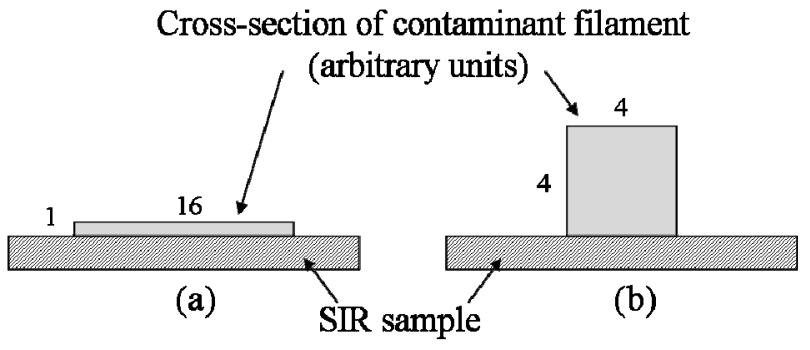

\begin{tabular}{|c|c|c|}
\hline Shape & a & b \\
\hline Area & 16 & 16 \\
\hline Open Perimeter & 18 & 12 \\
\hline Surface Contact & 16 & 4 \\
\hline
\end{tabular}

Figure 16. Contaminant cross-sectional area. 


\section{CONCLUSIONS}

The dc inclined plane test generates very reproducible results. In these tests, material differences can be identified in the results. For example in $3.15 \mathrm{kV}$ dc tests the eroded mass for materials $\mathrm{A}, \mathrm{B}$, and $\mathrm{C}$ were $3.5,4.7$ and $1.7 \mathrm{~g}$ with standard deviation of $1.4,1.1$ and $1.4 \mathrm{~g}$, respectively. Material $\mathrm{C}$ performed best, having the lowest mass loss due to erosion and erosion depth. As a result, it is considered to have a higher resistance to tracking and erosion. However, different material properties may affect the electrical stress in a test such that the nature of surface discharges change. As such, we are not only testing performance of different materials as a function of resistance to tracking and erosion, but also how the material affects discharge severity in a test.

In dc tests, there is evidence of: erosion of the positive electrode (anode) from electrolysis and oxidation of the bottom electrode due to high temperature arcing.

There is a clear difference between positive and negative dc test conditions. At 2.25, 2.7 and $3.17 \mathrm{kV}$ dc, positive dc tests have higher average leakage current, are more intermittent and produce deeper erosion and greater sample mass loss as compared to their equivalent negative test. The observed surface degradation pattern is also considerably different in each case. The likely contributing factors to the above are: shape and volume of conductive filaments on the surface, the electro-hydrodynamic behaviour of the contaminant, existing surface damage patterns and the effects of electrolysis.

The leakage current distribution from a dc test follows the normal distribution, suggesting there are a large number of different variables which contribute to the overall damage caused. As a result, it is not easy to pick a particular test attribute such as average leakage current which will always be indicative of the level of damage caused. Positive tests have a higher standard deviation and negative tests have a higher ratio of peak current to average current.

Experiments in which test polarities where reversed after $3 \mathrm{~h}$ show the criticality of surface condition in subsequent damage propagation irrespective of the previous polarity.

\section{ACKNOWLEDGMENTS}

The author would like to thank ABB for their support in this work, and their permission to publish.

\section{REFERENCES}

[1] M. A. R. M. Fernando and S. M. Gubanski, "Leakage Currents on Non-ceramic Insulators and Materials", IEEE Trans. Dielectr. Electr. Insul., Vol. 6, pp. 660-667, 1999.

[2] L. H. Meyer, J. H. Shesha, and E. A. Cherney, "Estimating Erosion on Polymeric Materials Using a Laser Based Model", IEEE Conf. Electr. Insul. Dielectr. Phenomena (CEIDP), pp. 337-340, 2005.

[3] L. Meyer, S. H. Jayaram, and E. A. Cherney, "Correlation of Damage, Dry Band Arcing Energy, and Temperature in Inclined plane Testing of Silicone Rubber for Outdoor Insulation", IEEE Trans. Dielectr. Electr. Insul., Vol. 11, pp. 424-432, 2004.

[4] V. M. Moreno and R. S. Gorur, "Ac and dc Performance of Polymeric Housing Materials for HV Outdoor Insulators", IEEE Trans. Dielectr. Electr. Insul., Vol. 6, pp. 342-350 1999.
[5] R. Sarathi, S. Chandrasekar, and N. Yoshimura, "Investigation of Tracking Phenomena in Outdoor Polymeric Insulation Material Under DC Voltages Using Wavelets", Trans. Power Delivery, Vol. 21, pp. 515-517, 2006.

[6] S. Chandrasekar, R. Sarathi, and M. G. Danikas, "Analysis of Surface Degradation of Silicone Rubber Insulation Due to Tracking Under Different Voltage Profiles", Archiv fur Elektroteknik, Springer, Berlin, Germany, Vol. 89, No. 6, pp. 489-501, 2006.

[7] "Electrical insulating materials under severe ambient conditions Test methods for evaluating resistance to tracking and erosion", BS EN 60587: British Standards, 2007.

[8] G. P. Bruce, S. M. Rowland, and A. Krivda, "DC inclined plane testing of silicone rubber formulations", IEEE Conf. Electr. Insul. Dielectr. Phenomena (CEIDP), Quebec City, Canada, pp. 196-199, 2008.

[9] K. N. Mathes and E. J. McGowan, "Surface Electrical Failure in the Presence of Contaminants: The Inclined-Plane Liquid-Contaminant Test", Trans., Part 1, Communications and Electronics, American Institute of Electrical Engineers, TEECA, pp. 281-289, 1961, AIEE Preprint 61-21.

[10] A. Krivda, L. E. Schmidt, X. Kornmann, H. Hillborg, H. Ghorbani, A. Ghorbandaeipour, M. Eriksson, "Inclined-Plane Tracking and Erosion Test according to the IEC 60587 Standard", IEEE Conf. Electr. Insul. Dielectr. Phenomena (CEIDP), Quebec City, Canada, pp. 263-267, 2008.

[11] H. Gleizer, J. H. Mason, and A. L. Tan, "Electrolytic Corrosion as an Adjunct to DC Tracking and Erosion on Insulators", 5th Inern. Conf. Dielectric Materials, Measurements and Applications, Brazil, pp. 135-138, 1988.

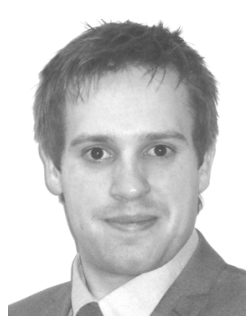

Graham Philip Bruce (S'05) was born in Middlesbrough, England in 1984. He received his M.Eng. degree from the University of Manchester, UK in 2006. He is currently studying for the Ph.D. degree in the University of Manchester, studying the ageing mechanisms of composite insulators under HVDC.

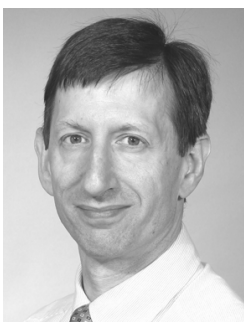

Simon M. Rowland (SM'07) was born in London, England. He completed his B.Sc. degree in physics at UEA and his Ph.D. degree at London University. He was awarded the IEE Duddell Premium in 1994 and became a FIEE in 2000. He has worked for many years on dielectrics and their applications. He has also been Operations and Technical Director multinational manufacturing companies. He joined The School of Electrical and Electronic Engineering in The University of Manchester as a Senior Lecturer in 2003 and was appointed Professor of Electrical Materials in 2009. He is Vice-President Admin. of the IEEE Dielectrics and Electrical Insulation Society (DEIS).

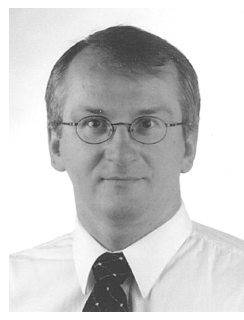

Andrej Krivda (M'96) was born in Humenne, Slovakia in 1967. He received his M.Sc. degree from Kosice University of Technology, Slovakia and Ph.D. degree from Delft University of Technology, the Netherlands. He spent one year at the Royal Institute of Technology, Stockholm, Sweden working on automated recognition of partial discharge patterns and four years at Queensland University of Technology, Brisbane, Australia working on outdoor insulation. He was awarded the Power Engineering Journal and the Journal of Electrical and Electronics Engineering, Australia, premiums for his work on overhead insulated mains in 2000. Since 2001 he has been with ABB Switzerland Ltd, Corporate Research, Baden-Daettwil, Switzerland. His main interests are outdoor insulation, classical music, partial discharges, jazz, neural networks, chess. In his free time he paints and exhibits his works in New York, Los Angeles, Zurich and Montreal galleries. 